\title{
The Four Development Stages of Social Medical Construction in Chinese Modern Society*
}

\author{
Fanmei Meng \\ Xiamen Huaxia College \\ Xiamen, China 361024
}

\author{
Wei Sun \\ Xiamen Weijian Committee \\ Xiamen, China 361000
}

\author{
Haishe Zhang \\ Xiamen Weijian Committee \\ Xiamen, China 361000
}

\begin{abstract}
In China, medical entities organized by private capital can be traced back to more than 2000 years ago. What this paper studies is the development period of modern Chinese society since the founding of new China. According to the characteristics of the form, scale, management, social impact, and social environment of the social management of doctors at different stages, the impact of the guidelines and policies promulgated by the government at different times on the social management of doctors has been combined. This paper puts forward the four-stage theory of the "budding period, embryonic period, initial development period, and rapid development period" in modern Chinese society, and further analyzes and proves on this basis.
\end{abstract}

Keywords-modern social medical construction; development stage; four-stage theory

\section{INTRODUCTION}

In China, social medical construction refers to various health institutions that carry out various diseases diagnosis and treatment activities with the help of social capital. There are many titles for these institutions, some are called "Min Ying Hospitals" (private hospitals) or "Si Li Hospitals" (private hospitals), and some are called "Si Ying Hospitals" (private hospitals), "non-public hospitals" and so on. In order to facilitate the definition of the concept, according to the "Notice of the State Council issued by the State Council on the promotion of certain policies and measures for accelerating the development of social medical treatment" issued by the State Council in 2015. It's the first time to use the official term "social medical treatment" in this notice. This article quotes this title to distinguish it from "government-run medical institutions", which commonly refers to the "public hospitals".

Judging from the concept of social medical construction, its development has a long history in Chinese society. It can be traced back to the Zhou and Qin Dynasties in the 2nd century BC. The entities providing medical services from the

*Fund Project: Xiamen Weijian Committee Guides Xiamen Social Science Research Project (Project Number: 2019C24).

CLC Number: R-012; Document Code: B. individual "barefoot doctors" to the various forms of timehonored Chinese medicine centers. The development of medical entities organized by private funds lasted for two thousand years. Western missionaries brought Christianity and Western medicine into China in the late Ming and early Qing dynasties. With the increasing influence of Western medicine in China, the application of modern Western medicine has gradually entered China in modern times. After the Opium War, the church hospital made western medicine appears in China in a complete institutional form, becoming the main form of social medical construction in Chinese society at that time. It has existed for decades, and the development of Chinese medicine has entered a downturn or even backward period since that time.

\section{The DeVElopment Stages of Social MedicAL CONSTRUCTION IN CHINESE MODERN SOCIETY}

Since the founding of the People's Republic of China in 1949, the modern social medical construction studied in this paper has been developing under the guidance of relevant policies in various periods of the new China. With the birth of New China and the establishment of China's socialist system, the development of Chinese society in social medical treatment has entered a special period. In the 21 st century, with the progress of the society and the improvement of people's economic and living standards, people's attention to the society has gradually changed from the previous economic development to the health of the whole people. In particular, the concept of great health has been put forward by the state, and people's demand for medical and health services has shown a multi-level and diversified trend. It's obvious to see that public hospitals with severe homogenization had not been able to meet the needs of people at all, so various forms of social medical construction have emerged. The author has combed and studied the development process of social medical construction in modern society, and analyzed the forms, scales, management methods, social influences, social environment and other aspects of social medical treatment at each stage. The author also put forward the four-stage theory of "sprouting period, embryonic period, initial development period, rapid 
development period" in modern Chinese society according to the different government policies and the medical guidelines in different periods.

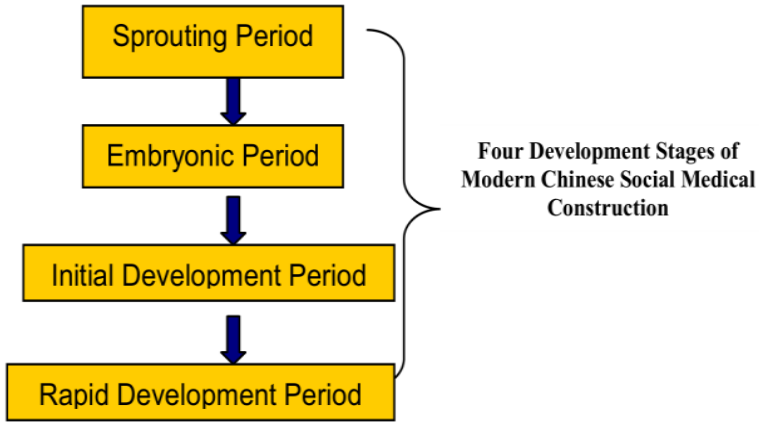

Fig. 1. Four development stages of modern Chinese social medical construction.

\section{A. Sprouting Period(1949-1978)}

Although the ignorant society of medical treatment was not born in a good time, it also laid a certain foundation for the development of medical treatment in the later society. Since the new China has just been established, and it is also the period when the hostile cultural trend of thought is most likely to return. The government has a strong sense of opposition to all commercial ideologies with a "privatized" nature. Therefore, some social enterprises that existed before the founding of New China had gradually disappeared due to various social ideologies.

According to the statistics of 1947, there are three types of institutions that provide medical and health services: one is the government office, there are 143 provincial medical institutions and 105 municipal medical institutions; the second is the church office, there are 520 missionary hospitals in various provinces and cities, mostly in the United States; the third is private clinics, and about 200,000 medical practitioners work in private clinics [1].

After the founding of the People's Republic of China in 1949, China adopted a multi-ownership economic policy. Two different measures were taken for hospitals and clinics. Large hospitals with various forms of capital left over from before liberation were gradually nationalized, including hospitals established by various forms of capital at home and abroad, and individual practitioners and clinics were allowed to continue to exist and develop. Later, non-government medical institutions gradually decreased under the climax of nationwide socialist transformation. By September 1966, the state stopped the public-private joint interest payment policy, most self-employed doctors were closed, some joint clinics were turned into collective ownership, and social medical construction institutions basically disappeared [2].

\section{B. Embryonic Period (1978-1993)}

The social medical construction has not yet entered the "access" level of at this stage, but it has begun to show a market phenomenon that is in short supply. The supply market for providing medical services has become active under the influence of the market mechanism. At the end of the 1980s, a group of social medical doctors represented by the "Putian Department" began to appear. However, due to the lack of policy support and access mechanism, the social management of this stage lacked supervision and chaos. The main features are: small, chaotic, and more.

After the Chinese eleventh CPC Central Committee Third Plenary Session, the country shifted its focus to economic construction. The individual economy and the private economy also became an important component of the economy. In 1980, the State Council approved the Ministry of Health's "Request for Report on Allowing Individuals to Open Practices", it recognized the legitimacy of individual medical institutions, social run medicine gradually developed. In 1985, the State Council approved the "Report on Several Policy Issues Concerning Health Reform" of the former Ministry of Health, it has further clarified the form of support for individual practice of medicine [3], but the pace of social medical construction development is slow and small. In 1983, the earliest private hospital in ChinaGuangzhou Yishou Hospital was established; it was named "China's first private joint-stock general hospital". In January 1985, the first private hospital in Baoding City was founded by the female doctor Wang of Hebei College of Traditional Chinese Medicine [4]. In the late 1980s, social entities represented by the Fujian Putian department began to enter the medical market with a big scale. Most of the national social medical institutions are still run by Putian people even now. The establishment of social-related medical policies changed from the tight to loose and the establishment of various forms of social capital medical institutions have marked the early embryonic form of modern Chinese social medical construction.

In the meantime, social medical construction is just like the bamboo shoots after a spring rain. Different social enterprises of various scales and forms have been established, and problems have gradually emerged. According to the development of representative social hospitals in Shanghai in the 1980s, the social medical construction institutions were complicated in their own sources; the sources of medical personnel were complicated; the necessary rules and regulations were lacking; the fees were chaotic and the medical staff changed frequently; the business scope was expanded at will. All of them rely on borrowing houses, privately hiring medical technicians, etc. Problems such as how to correctly guide, strengthen supervision, and promptly deal with problems reported by the public are beginning to appear, and the voice of rectifying and governing social medical construction services is emerging again. In addition, the township health centers all over the country have experience reform nearly for ten years at the time. Because it has no new breakthroughs in management and service system, the reform measures of original power has reached a larger level. Many township health centers are faced with various multi-channel medical competitions and the new contradiction of reduced input and soaring expenditure.

The State promulgated the "Regulations on the Administration of Medical Institutions" in 1994 in order to correctly guide the development of social medical practitioners in the right direction and resolve and 
circumvent the contradiction of the period of social medical construction.

\section{Initial Development Period (1994-2008)}

The promulgation of the "Regulations on the Administration of Medical Institutions" marks the beginning of the third period of the development of social medical construction in modern Chinese society. The "Regulations" clearly state that "It's necessary to encourage the establishment of medical institutions in various forms". China's medical institutions are divided into five types according to the forms of ownership, namely owned by the whole people, collective ownership, private ownership, Sinoforeign joint venture and other forms. It's the first time for the medical institutions in the form of "privately-owned" and "Sino-foreign joint venture" has been established in the form of practicing license. The form standards for social medical treatment have been formally established since that time, the management model has been gradually standardized, and government supervision has a certain degree of rules to follow. The recognition of social medical practitioners has gradually improved, and the social environment for social medical construction has been improved. The development of modern Chinese society is gradually getting on the right track.

However, the state and society attach more importance to public medical institutions due to historical reasons and different national conditions. The development of public hospitals has obvious advantages, and the development of social medical construction is still relatively slow. In the late 1980s and early 1990s, some people have taken advantage of the policy to set up the social medical service, but they are not able to seriously implement the regulations. It has leaded both praise and criticism on social medical construction." The direction of medical treatment is deviated, the wind is not serious," "the quality is inferior, the human life is disregard." The society calls on the government to rectify the market. The call for "enhancing health law enforcement and strengthening the management of the whole industry" has sounded again. In 1997, the "Decision of the Central Committee of the Communist Party of China and the State Council on Health Reform and Development" clearly stated that "the organization of medical institutions should be based on the state and the collective and supplemented by other social forces and individuals." After the introduction of the "Supplementary Opinions", the above-mentioned bad phenomena of social medical construction have been effectively curbed in the 21 st century. The development of social medical construction has also begun to focus on its own medical technology innovation, improving the level of nursing services, strengthen its management and other aspects.

During this period, individual local governments also issued relevant guidance. In 2004, the Fujian Provincial Reform and Opening Office, the Health Department, and the Department of Finance jointly drafted "Several Opinions on "Accelerating the Development of Private Hospitals" [5], which is an early instruction for the local guidance on social medical construction and provides a clear direction for developing the basic principles. It has improved the external environment, encouraged public hospital reform, strengthened supervision and management, and promoted the healthy development of hospitals. At the same time, many areas across the country have implemented the new policy of medical reform, and accumulated valuable experience on how to guide social capital to set up private hospitals through compensated transfer and reorganization, share in the restructuring and overall auction of state-owned enterprise hospitals as well as guide nongovernmental capital to set up private hospitals.

\section{Rapid Development Period (2009 to Now)}

With the improvement of people's living standards and the rapid development of foreign medical standards, the people's demand for multi-level and diversified medical and health services has become more and more urgent, and the contradiction between supply and demand has become more prominent. The state's support policies for social medical construction have been intensively introduced, which has greatly promoted the development of social medical construction. Various forms and levels of social medical construction have effectively supplemented the vacancies and deficiencies of public medical service institutions. In order to improve the satisfaction and loyalty of patients in their medical services, social medical entities in various circles have gradually shifted their focus to how to improve the hospital's own management level, nursing service level, medical technology level and optimize the hospital environment.

The report of the 17th National Congress of the Communist Party of China pointed out that "the establishment of a medical and health system with Chinese characteristics and the gradual realization of the goal of basic medical and health services for all people is the striving goal", the task of deepening the reform of the medical system is arduous and urgent. In 2009, the State Council issued the "Central Committee of the Communist Party of China" on deepening medical and health care. It has established the principle of "adhering to non-profit medical institutions as the main body, regarding for-profit medical institutions as a supplement, taking public medical institutions as the leading and combining non-public medical institutions to develop together". Since then, China's medical reform has appeared on the scene. It's the first time to comprehensively put forward the guiding ideology, basic principles and overall objectives for medical reform, and clarifies that social medical treatment is an important supplement to further improve the medical service system. It marks that the Chinese social medical construction has entered a new period of development. It has also clarified the social medical treatment is a supplement to the urgent need for the construction of the entire social medical system from the supply to the demand.

After the promulgation of the Central Committee's "Opinions on Reform" document, in order to help all regions and concerned departments to further emancipate their minds and change their concepts, seize the time to clean up the industry, revise the access, practice and supervision of social 
medical institutions, formulate and improve practical implementation rules and supporting documents in a timely manner, and remove policy obstacles. A series of policy documents were also closely introduced. In 2010, the State Council issued the "Several Opinions on Encouraging and Guiding the Healthy Development of Private Investment" [7] and the "Notice on Further Encouraging and Guiding Social Capital to Deploy Medical Institutions" [8] In 2012, the 18th National Congress of the Communist Party of China further proposed to deepen the reform of public hospitals and encourage the society to run medical treatment. In 2015, the State Council issued the "Notice on Printing and Distributing Certain Policies and Measures for Accelerating the Development of Social Medicines by the General Office of the State Council" [9]. In 2017, the State Council issued the "Opinions of the General Office of the State Council on Supporting Social Forces to Provide Multi-level Diversified Medical Services".[10] In 2018, all provinces, autonomous regions, and municipalities directly under the Central Government successively issued local implementation documents on "Implementation Opinions on Supporting Social Forces to Provide Diversified Medical Services on Multiple Sides". It's necessary to further relax the access of medical institutions, control the scale of public hospitals, expand investment and financing channels, promote resource flows and sharing, optimize the environment for the development of social medical construction, and clearly propose to include social medical institutions in the scope of medical insurance. Social medical construction has entered a new period of rapid development have entered a new period of rapid development.

According to the data compiled by the National Health and Safety Commission and the China Business Research Institute, by the end of November 2018, the number of medical and health institutions nationwide increased by 11,217 over the same period of the previous year with an increase of $1.13 \%$, and the total number of hospitals was 32,000 , of which 20,404 were private hospitals. The number of public hospitals decreased by 109 , and that of social medical construction hospitals increased by 2,291 compared with the same period in 2017. The types of social medical construction have gradually penetrated into a number of subdivided medical services, including ophthalmology, orthopedics, oral, maternity, pediatrics, oncology, mental, medical beauty and other specialties as well as Chinese medicine, rehabilitation, nursing, physical examination, etc. The awareness of medical brands has increased, and some powerful social medical institutions have actively worked to form excellent medical teams, aiming at cutting-edge disciplines and providing a variety of special medical services [11].

\section{CONCLUSION}

Since the founding of the People's Republic of China, the development of modern Chinese social medical institutions has lasted for 70 years. It has experienced from the germination to the beginning of the embryo, and then into the initial development and then to the current period of rapid growth. It developed from the initial prohibition to the current encouragement and support; from State-to-region governments at all levels have gradually investigated and understood various factors affecting the development of social medical treatment; from government supervision, improvement of social environment, support of medical insurance system, government incentive policy, and optimization of urban medical service institution institutions In terms of policy adjustments, the optimization of the business environment has provided a fertile ground for the development of social medical services, which has given birth to a multi-level, diversified medical service for the rapid growth of medical services. If the past decade is a decade in which social medical practitioners are actively exploring, then it is foreseeable that the next decade will be a decade in which the overall face of social medical treatment has undergone major changes.

\section{REFERENCES}

[1] Lu Hong, Jin Xing. Research on the status and development of private hospitals in Shanghai. China Hospital Management, 2006, 26 (12): 11-14. (in Chinese)

[2] Huang Duan. Research on the development strategy of non-public hospitals in China [D]. Tianjin Medical University, 2012. (in Chinese)

[3] State Council. Notice of the State Council on the approval of the Ministry of Health's report on certain policy issues related to health work reform [Z]. Beijing

http://www.chinalawedu.com/, 1985-04-25. (in Chinese)

[4] Liu Yan, Qi Lulu, Zhu Qian, Zhu Tongyu. The history of social capital management in China and the development of related policies [J]. Chinese Hospital Management, 2014, 34 (05): 14-17. (in Chinese)

[5] Fujian Province issued several opinions on accelerating the development of private hospitals, and the Fujian Provincial Health Department implemented score management for medical institutions' violations [J]. China Health Resources, 2003 (02): 71. (in Chinese)

[6] "Opinions of the Central Committee of the Communist Party of China on Deepening the Reform of the Medical and Health System" [A] China Rehabilitation Medical Association Senior Rehabilitation Professional Committee. China Rehabilitation Medical Association Seventh National Congress of Geriatrics and Rehabilitation Academic Conference [C]. China Rehabilitation Medical Association Senior Rehabilitation Professional Committee: China Rehabilitation Medicine Association, 2012: 6. (in Chinese)

[7] Several opinions of the State Council on encouraging and guiding the healthy development of private investment [J]. SME Management and Technology (Middle), 2011 (05): 28-31. (in Chinese)

[8] State Council. Notice on further encouraging and guiding social capital to hold opinions of medical institutions [Z].2010. (in Chinese)

[9] State Council The State Council and the General Office of the State Council issued a notice on promoting a number of policies and measures for the accelerated development of social medical services [Z].2015-06-11. (in Chinese)

[10] Su Zheng. State-run papers support social forces to provide multilevel diversified medical services [J]. Journal of Traditional Chinese Medicine Management, 2017, 25 (10): 190. (in Chinese)

[11] China Business Research Institute. Policy encourages social medical institutions to accelerate development Data statistics of medical and health institutions in 2018 [EB/OL].

http://www.askci.com/. 2019-02-20. (in Chinese) 